\title{
Probing polyoxometalate-protein interactions using molecular dynamics simulations
}

\author{
Albert Solé-Daura, ${ }^{a}$ Vincent Goovaerts, ${ }^{b}$ Karen Stroobants, ${ }^{b}$ Gregory Absillis, ${ }^{b}$ Pablo Jiménez-Lozano, ${ }^{a}$ \\ Josep M. Poblet, ${ }^{a}$ Jonathan D. Hirst, ${ }^{c}$ Tatjana N. Parac-Vogt, ${ }^{b}$ Jorge J. Carbó ${ }^{\star a}$
}

\begin{abstract}
The molecular interactions between the $\mathrm{Ce}(\mathrm{IV})$-substituted Keggin anion $\left[\mathrm{PW}_{11} \mathrm{O}_{39} \mathrm{Ce}\left(\mathrm{OH}_{2}\right)_{4}\right]^{3-}(\mathrm{CeK})$ and hen egg white lysozyme (HEWL), was investigated by molecular dynamics (MD) simulations. We compared the analysis of CeK with the Ce(IV)substituted Keggin dimer $\left[\left(\mathrm{PW}_{11} \mathrm{O}_{39}\right)_{2} \mathrm{Ce}\right]^{10-}\left(\mathrm{CeK}_{2}\right)$ and the $\mathrm{Zr}(\mathrm{IV})$ substituted Lindqvist anion $\left[\mathrm{W}_{5} \mathrm{O}_{18} \mathrm{Zr}\left(\mathrm{OH}_{2}\right)(\mathrm{OH})\right]^{3-}(\mathrm{ZrL})$ in order to understand how POM features such as the shape, the size, the charge or the type of incorporated metal ion influence the POM $\cdots$ protein interactions. Simulations revealed two regions of the protein, in which the $\mathrm{CeK}$ anion interacts strongly: the cationic sites formed by Arg21 on one hand and by Arg45 and Arg68 on the other. The two sites can be related with the observed selectivity in the hydrolytic cleavage of HEWL. The POMs chiefly interact with the side chains of the positively charged (arginines and lysines) and the polar uncharged (tyrosines, serines and aspargines) residues via electrostatic attraction and hydrogen bonding with the oxygens of the POM framework. The CeK anion shows higher protein affinity than the $\mathrm{CeK}_{2}$ and $\mathbf{Z r L}$ anions, because it is less hydrophilic and it has the right size and shape for stablishing interactions with several residues simultaneously. The larger and more negatively charged $\mathrm{CeK}_{2}$ anion has a high solvent-accessible surface, which is suboptimal for the interaction, while the smaller ZrL anion is highly hydrophilic and it cannot interact simultaneously with several residues so efficiently.
\end{abstract}

\section{Introduction}

Polyoxometalates (POMs) are a versatile and tunable class of inorganic polynuclear metal-oxygen clusters. ${ }^{[1],[2]}$ These molecules are built up from oxo-bridged early transition metals in their highest oxidation state, most notably Mo, $\mathrm{W}$ and $\mathrm{V}$. The removal of a $\mathrm{W}=\mathrm{O}$ unit from the plenary structure of the POMs generates anionic lacunary species that can coordinate a diversity of metal ions. This expands the variety of POM structures, resulting in their application in the fields of catalysis, ${ }^{[3]}$

[a] A. Solé-Daura, Dr. P. Jiménez-Lozano, Prof. Dr. J. M. Poblet, Dr. J. J. Carbó

Departament de Química Física i Inorgànica

Universitat Rovira i Virgili

Marcel.lí Domingo, 143007 Tarragona (Spain)

E-mail: j.carbo@urv.cat

[b] Dr. V. Goovaerts, Dr. K. Stroobants, Dr. G. Absillis, Prof. Dr. T. N Parac-Vogt.

Laboratory of Bioinorganic Chemistry

KU Leuven

Celestijnenlaan 200F 3001 Heverlee (Belgium)

[c] Prof. Dr. J. D. Hirst

School of Chemistry

University of Nottingham

University Park, Nottingham NG7 2RD (United Kingdom)

Supporting information for this article is given via a link at the end of the document.((Please delete this text if not appropriate)) material science ${ }^{[4]}$ and medicine. ${ }^{[5]}$ The metal substitution provides a custom-made coordination chemistry and reactivity with catalytic applications ranging from alkene epoxidation by group IV-substituted $\mathrm{POMs}^{[6]}$ to the splitting of water by Ru- and Co-substituted ones. ${ }^{[7]}$ More interesting in this context is their biological activity, which includes in vitro and in vivo anticancer, antiviral and antibiotic activity. ${ }^{[5]}$ POMs can also interact with proteins causing enzyme inhibition activities. ${ }^{[8]}$ For years, Yonath et al. have used polyoxometalates as "super-heavy atoms" in the crystal structure determination of ribosome. ${ }^{[9]}$ Although little is known about the exact molecular mechanism responsible for POM biological activity, the importance of the polyoxometalate size, shape and charge, as well as the kind of incorporated metal ion has been recognized.

In recent years Parac-Vogt et al. have studied the POM hydrolytic activity towards the highly inert peptide bond in biomolecules such as dipeptides and oligopeptides, ${ }^{[10]}$ and more importantly, reported the first examples of selective hydrolysis of proteins by POMs. ${ }^{[11],[12],[13]}$ The active POMs include different structures of $\mathrm{Ce}(\mathrm{IV})$ - and $\mathrm{Zr}(\mathrm{IV})$-substituted anions, which initially were applied to the hydrolysis of hen egg-white lysozyme (HEWL), ${ }^{[11]}$ and more recently to human serum albumin (HSA), ${ }^{[12]}$ and myoglobin. ${ }^{[12]}$ It was observed that the peptide bond cleavage sites are close to positively charged protein surface patches. Therefore, it was postulated that the electrostatic interactions with the negatively charged POM structures lead to the selective hydrolysis in an enzyme-like recognition scheme. ${ }^{[11]-[15]}$ Nevertheless, so far no direct proof for the electrostatic nature of these POM $\cdots$ protein interactions has been presented.

Understanding the physicochemical foundations of the interactions between POMs and biomolecules might have important implications for medical and biochemical applications of POMs beyond selective peptide hydrolysis. In this regard, computational simulations could facilitate the understanding of the molecular properties that govern the interaction in order to further develop metal-substituted POMs with specific interaction properties. Although these tools have been largely employed to study POM chemistry, ${ }^{[16]}$ the study of POM-protein interactions at molecular level is still a largely unexplored area.

There have been a number of docking studies exploring the binding locations for POMs with proteins, but due to the intrinsic limitations of this methodology little was revealed about the driving forces that are responsible for the specific interactions. ${ }^{[16]}$ These studies proposed that POMs interact mainly with positively charged amino acids such as Lys, His or Arg, or with polar uncharged ones such as Asn, Ser, Cys, Thr or Gln. For example, Hill et al. showed that Nb-containing POMs inhibit HIV1 protease by binding to a cationic pocket of lysine residues away from the active site. ${ }^{[17] g}$ Similar findings were derived from experimental studies, which identified electrostatic effects as the main factor in the interaction of POMs with biomolecules based on luminescence of Eu-substituted POMs, the fluorescence of 
tryptophan residues, isothermal titration calorimetry (ITC), and NMR and circular dichroism (CD) spectroscopy. ${ }^{[11]-[19]}$ For example, $\mathrm{Qu}$ et al. proposed that POMs bind to the positively charged His13-Lys16 cluster region of amyloid $\beta$-peptides associated with Alzheimer's disease. ${ }^{[18] d}$ It was also observed that the POMs can bind sufficiently tightly to cause structural change in basic fibroblast growth factor (bBGF). ${ }^{[18] \mathrm{b}}$ More specifically, recent studies using model amino acids and peptides attributed the mechanism of interactions with biomolecules to electrostatic interactions and hydrogen bonds between amino acids and the negative charges of POMs. ${ }^{[19]}$

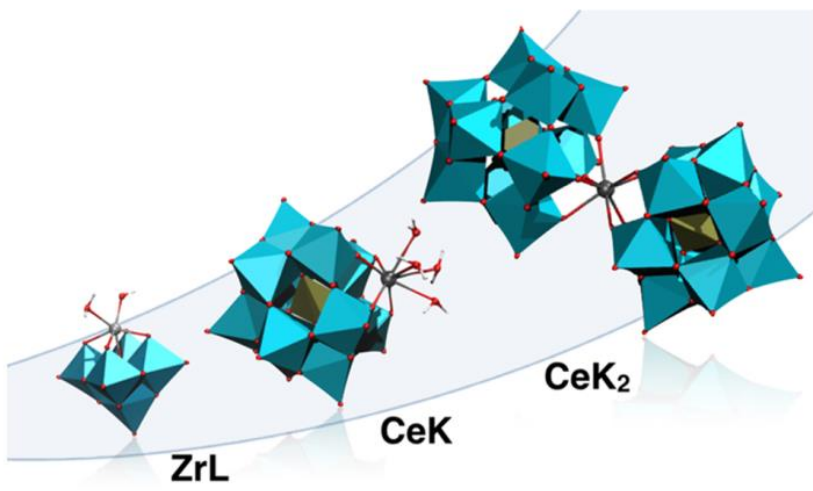

Figure 1. Polyhedral representation of the anions $\left[\mathrm{PW}_{11} \mathrm{O}_{39} \mathrm{Ce}\left(\mathrm{OH}_{2}\right)_{4}\right]^{3-}(\mathbf{C e K})$, $\left[\mathrm{Ce}\left(\mathrm{PW}_{11} \mathrm{O}_{39}\right)_{2}\right]^{10-}\left(\mathrm{CeK}_{2}\right)$ and $\left[\mathrm{W}_{5} \mathrm{O}_{18} \mathrm{Zr}\left(\mathrm{OH}_{2}\right)(\mathrm{OH})\right]^{3-}(\mathrm{ZrL})$

Interestingly, $\mathrm{Qu}$ et al. found an apparent trend related to POM composition: the larger negative charge, the higher the binding affinity, and the stronger the inhibitory effect. ${ }^{[18] d}$ However, if one considers the charge density of the anion instead of the overall charge, the inactive POMs are not only the least charged but also the smallest anion carrying one of the highest charge densities among the series. Thus, we suspect that binding might require cooperation of electrostatic (high negative charge) and hydrophobic (accessible surface) forces. Moreover, hydrophobic and electrostatic interactions in the most general sense are non-specific effects that would not explain by themselves the specificity of interaction sites, the selective enzyme-like recognition, nor the dependence on POM size and shape. Therefore, we believe that it is necessary to analyse the factors underlying the interaction of POMs with biomolecules beyond size-specific electrostatic effects in order to obtain a full picture of the physicochemical foundations in these process.

Herein, we performed molecular dynamics (MD) simulations of three different POM structures with HEWL in aqueous solution. The three POMs are Ce-substituted Keggin-type anion $\left[\mathrm{PW}_{11} \mathrm{O}_{39} \mathrm{Ce}\left(\mathrm{OH}_{2}\right)_{4}\right]^{3-} \quad(\mathrm{CeK})$ the corresponding 1:2 dimer $\left[\mathrm{Ce}\left(\mathrm{PW}_{11} \mathrm{O}_{39}\right)_{2}\right]^{10-}\left(\mathrm{CeK}_{2}\right)$ and the $\mathrm{Zr}$-substituted Lindqvist-type anion $\left[\mathrm{W}_{5} \mathrm{O}_{18} \mathrm{Zr}\left(\mathrm{OH}_{2}\right)(\mathrm{OH})\right]^{3-}(\mathrm{ZrL})$, which differ in the overall charge, the size, the shape and the type of substituted metal (see Figure 1). Lysozyme represents a simple model protein for fundamental studies, but more importantly, it has been demonstrated that Ce-substituted POM acted as a selective protease cleaving HEWL at the peptide bonds Trp28-Val29 (site I) and Asn44-Arg45 (site II). Both Eu(III) luminescence and tryptophan fluorescence studies indicated that the POM binds the protein near these cleavage sites. ${ }^{[14]}$ Moreover recently, Parac-Vogt et al. reported the co-crystallization of a non- covalent complex between lysozyme and the analogous $\mathrm{Zr}$ substituted Keggin-type anion and its characterization via X-ray analysis. ${ }^{[20]}$ The simulations of CeK with HEWL protein performed in this work should provide additional information regarding the dynamics of the interaction and the relative binding strengths of individual amino acids. Moreover, direct comparison between POMs will shed light on the structural factors governing the interactions between the POMs and the biomolecules.

\section{Computational details}

The systems were simulated by classical MD using the GROMACS 4.5.4 software ${ }^{[21]}$ and the AMBER99 force field, ${ }^{[22]}$ which has been successfully employed to study the aggregation behaviour of POMs in solution by Chaumont and Wipff. ${ }^{[23]}$ The potential energy $U$ is empirically described by a sum of bond, angle, and dihedral deformation energies (bonding terms) and pair-wise additive 1-6-12 (electrostatic and van der Waals, nonbonding terms) interactions between non bonded atoms.

The parameters for the Ce-substituted POMs were obtained following the procedure of Bonet-Avalos, Bo, Poblet et al. ${ }^{[24]} \mathrm{We}$ used CHELPG atomic charges derived from the electrostatic potential. They were obtained with the Gaussian09 package ${ }^{[25]}$ at the DFT level (BP86 functional) ${ }^{[26]}$ using the LANL2DZ basis se ${ }^{[27]}$ for $\mathrm{W}, \mathrm{O}$ and $\mathrm{H}$ atoms, and the MWB28 basis set ${ }^{[28]}$ for $\mathrm{Ce}$. Solvent effects were included in geometry optimizations by using the IEF-PCM model[29] as implemented in Gaussian09 package. ${ }^{[25]}$ The set of Lennard-Jones parameters for $\mathrm{W}$ and $\mathrm{O}$ atoms were taken from previous work, ${ }^{[24]}$ and those for Ce were taken from UFF force field. ${ }^{[30]}$ Parameters for ZrL were taken from previous studies. ${ }^{[31]}$ The geometry of the $8+$ charged HEWL was taken from protein data bank (PDB) database (PDB ID: 3IJV). ${ }^{[32]}$ For the MD simulations with $\mathrm{CeK}$, the protein was embedded in a water solvent box of dimensions $73.1 \times 68.8 \times$ $77.1 \AA$, one POM molecule $(q=-3)$ and five chloride ions to neutralize the system. MD simulations with ZrL were performed in a water solvent box of dimensions $75.7 \times 78.4 \times 79.1 \AA$, one POM molecule $(q=-3)$ and five chloride atoms to neutralize the system. For simulations with $\mathbf{C e K}_{2}$ the size of the box was 75.7 $\times 78.4 \times 79.1 \AA$ for the runs starting at the vicinity of protein site I and $73.1 \times 68.8 \times 77.1 \AA$ for those of site II. One POM molecule $(q=-10)$ and two $\mathrm{Na}^{+}$ions were added to neutralize the system.

Water was represented with the TIP3P model. ${ }^{[33]}$ All simulations were performed with 3D-periodic boundary conditions using an atom cutoff of $14 \AA$ for 1-4 van der Waals and of $10 \AA$ for 1-4 Coulombic interactions and corrected for long-range electrostatics by using the particle-particle mesh Ewald (PME) summation method. ${ }^{[34]}$ The simulations were performed at $300 \mathrm{~K}$ starting with random velocities. The temperature was controlled by coupling the system to a thermal bath using the Berendsen algorithm ${ }^{[35]}$ with a relaxation time of 0.5 ps to keep the NVT microcanonical conditions throughout the simulation. Newton equations of motion were integrated using the leap-frog algorithm, ${ }^{[36]}$ and a time step of $1 \mathrm{fs}$. The bonds with hydrogens were restrained using the LINCS algorithm. ${ }^{[37]}$ Starting either at the vicinity of site I or site II, we run 5 independent simulations of $20 \mathrm{~ns}$ for each POM at each site. Before the production runs, the systems were equilibrated 
with 5000 steps of energy minimization followed by simulations of 250 ps at constant volume (NVT).

\section{Results and Discussion}

\section{MD study of $\left[\mathrm{PW}_{11} \mathrm{O}_{39} \mathrm{Ce}\left(\mathrm{OH}_{2}\right)_{4}\right]^{3-}$ anion with $\mathrm{HEWL}$ in} solution.

Initially, we simulated the monomeric Ce-substituted Kegginsolution. Experimentally, the 1:2 dimeric structure $\left[\mathrm{Ce}\left(\mathrm{PW}_{11} \mathrm{O}_{39}\right)_{2}\right]^{10-}\left(\mathrm{CeK}_{2}\right)$ was in fact the complex employed in the selective hydrolysis. ${ }^{[10]}$ However, this species is a highly unlikely catalyst because the coordination sphere of $\mathrm{Ce}(\mathrm{IV})$ is fully saturated by coordination to oxygen atoms of the POM framework. Since hydrolysis requires the binding of the Ce metal acting as a Lewis acid to the amide carbonyl, it was proposed that the interaction with protein induces dissociation of the dimeric species $\mathrm{CeK}_{2}$ to the monomeric CeK POM. ${ }^{[11]}$ Some posterior evidence has supported this hypothesis. The analogous $\mathrm{EuK}_{2}$ dimer was shown to dissociate leading to monomeric EuK, which is able to bind to amino acids. ${ }^{[14] a}$ Similarly, when the analogous $\mathrm{Zr}$ dimer $\mathbf{Z r K}_{2}$ was used for cocrystallization with HEWL, the resulting crystal structure showed exclusively the presence of the $\mathrm{Zr}$-substituted monomeric species, ZrK. ${ }^{[20]}$
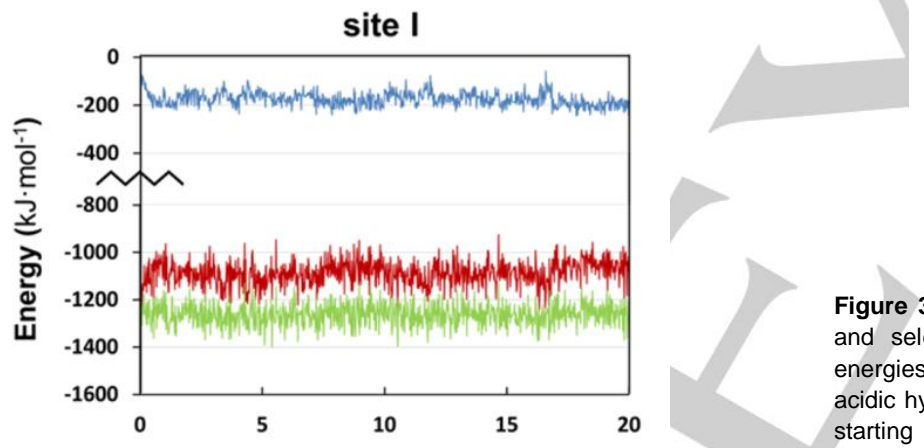
type anion $\left[\mathrm{PW}_{11} \mathrm{O}_{39} \mathrm{Ce}\left(\mathrm{OH}_{2}\right)_{4}\right]^{3-}(\mathrm{CeK})$ with $\mathrm{HEWL}$ in aqueous

the solvent (red line) and the whole system (green line) along a representative trajectory of $20 \mathrm{~ns}$ (see Supporting Information for the other trajectories). The graphs in Fig. 3 collect the analysis of the interaction of CeK with the individual amino acids averaged over $100 \mathrm{~ns}$ of dynamics trajectories: the average energy strength in bars and the percentage hydrogen bond lifetimes in lines. These simulations allowed us to identify the direct CeK $\cdots$ HEWL interaction, to characterize and evaluate the interactions with individual amino acids and their nature.

\section{site}
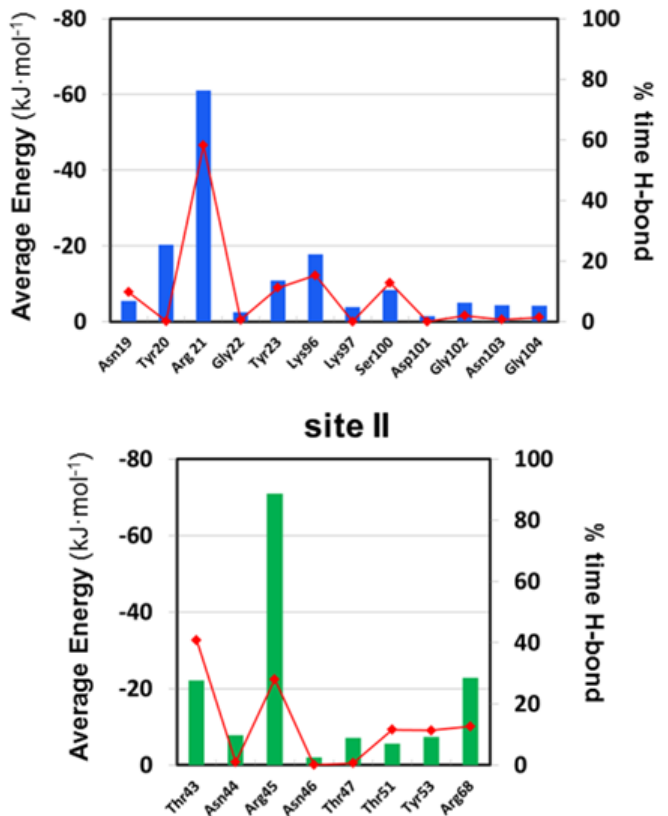

Figure 3. Analysis of amino acid specific interaction between the CeK anion and selected individual AAs of HEWL. Average non-bonding interaction energies in $\mathrm{kJ} \cdot \mathrm{mol}^{-1}$ (bars), and percentage of hydrogen bond persistences for acidic hydrogens of amide bond and side chains (lines) along the simulations starting at vicinity of site I (top) and II (down). The values are quantified at every 4 ps time frame over 100 ns MD trajectories.

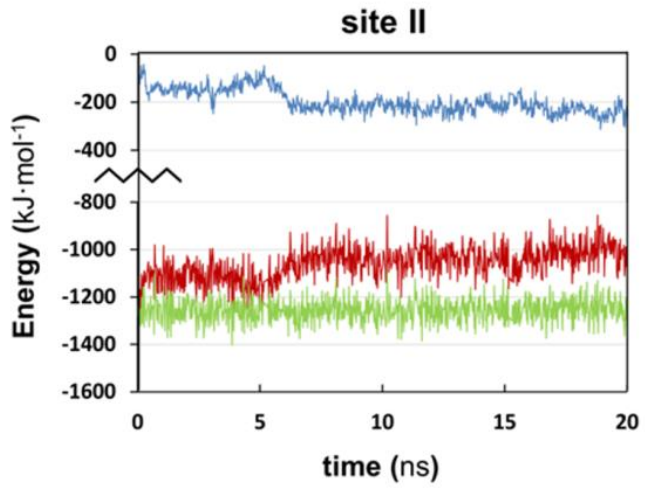

Figure 2. Non-bonding interaction energies (in $\mathrm{kJ} \cdot \mathrm{mol}^{-1}$ ) of the CeK anion with HEWL (blue line), with the solvent (red line), and with the whole system (green line) as a function of the time (ns) for simulations starting at vicinity of site (top) and // (down). Representative 20 ns run.

We performed two sets of simulations starting with the CeK anion placed at the vicinity of each of the known cleavage sites of HEWL (I and II). Fig. 2 plots the classical non-bonding energy for the interactions of the CeK anion with the protein (blue line),
For all the runs performed the interaction between the CeK anion and the HEWL is appreciable and remains present during most of the simulation time with non-bonding interaction energies averaging $-178 \mathrm{~kJ} \cdot \mathrm{mol}^{-1}$ for site $\mathrm{I}$ and $-161 \mathrm{~kJ} \cdot \mathrm{mol}^{-1}$ for site II (see Fig. 2 and Fig. S1 and S2 in Supporting Information). As a general trend, as the interaction with the protein strengthens, the solvent interaction energy lowers because the CeK anion has to remove the solvation shell to access protein surface. This can be seen in Fig. 2, where blue and red lines represent protein and solvent interaction energies, respectively. From the evolution of the interaction energy, we could also identify different time periods corresponding to different interaction modes of the CeK anion. In the simulations starting at the vicinity of site I, the CeK anion interacts at the $\alpha$-helical part of the structure outside of an entrance channel to cleavage site I that is buried in a hydrophobic pocket of the protein. As Fig. 3 shows, the most strongly interacting amino acid is Arg21; the interaction is present during the whole 100 ns sampling. Then the CeK anion can interact with Ser100 and with either amino acids on the left- or the right-hand side of the entrance channel (Lys96 and Lys97 or Tyr23, respectively). Fig. 4 shows a 
representation of the two portions of the protein surface that interact with the CeK anion, and Fig. 5 and 6 show illustrative snapshots of the CeK...HEWL interactions at the two different regions close to site I. Thus, the Arg21 anchors the CeK anion acting as a flexible hinge that places the POM at the one or the other side of the protein surface, or more embedded in the solvent.

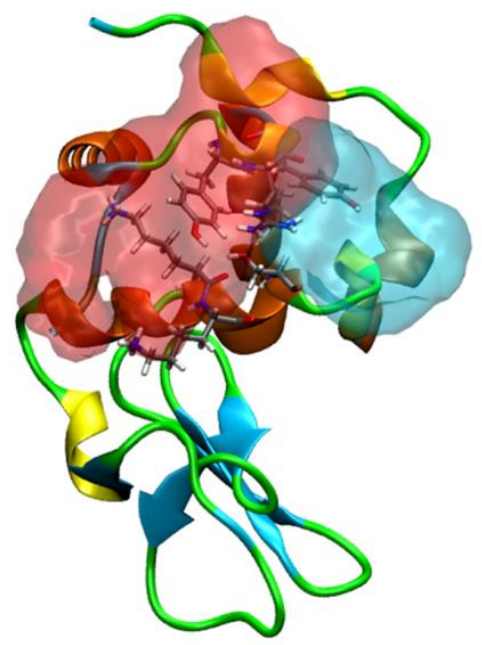

Figure 4. Representation of the volumetric density for the CeK anion contact with HEWL (POM $\cdots$ protein distance $<3.5 \AA$ ) along the 100 ns trajectories. Two protein surface regions differentiated by colours. Red area involving Lys96 and Lys97 and blue area involving Tyr23. Residues Arg21 and Ser100 are common in both areas.

In the simulation at the vicinity of site II, the CeK anion adsorbs onto the protein's surface, interacting directly with the amino acids of cleavage site II, which are exposed to the solvent in the $\beta$-strand region. In fact, the most strongly interacting amino acid in this set of simulations is Arg45 belonging to cleavage site II (see Fig. 3, lower panel). This interaction persists for most of the simulation, and some additional ones can occur simultaneously with amino acids such as Arg68, Tyr53, Thr43 and Thr51 (Fig. 3, lower panel) that contribute to the stability of the CeK $\cdots$ HEWL complex. Fig. 7 shows an illustrative snapshot in which this additive interaction can be observed: strong interaction with positively charged amino acids Arg45 and Arg68 at different protein regions, and with polar amino acids Tyr53, Thr43 and Thr51. In both cases, the CeK anion interacts mostly through the POM framework, with the hydrophilic $\mathrm{Ce}\left(\mathrm{H}_{2} \mathrm{O}\right)_{4}$ moiety pointing towards the solvent. The binding sites and the orientation of CeK anion revealed by dynamic simulations fully agree with the positions of the $\mathrm{Zr}$ substitute Keggin-type anions co-crystallized with HEWL. ${ }^{[19]}$

As illustrative snapshots in Fig. 5, 6 and 7 show, the CeK anion can be in direct contact with the protein surface forming hydrogen bonds with the amino acids side chains through the most basic oxygen atoms of the POM framework. Several amino acids of different sections of the protein structure interact simultaneously with the anion in an additive manner, and both the terminal and the bridging oxygen atoms act as hydrogen acceptors. For example in the first snapshot of site I (Fig. 5), the side chains of Ser100 and Tyr23 form hydrogen bonds with the terminal oxo groups of the POM framework $\left(\mathrm{O}-\mathrm{H} \cdots \mathrm{O}_{\mathrm{POM}}\right.$ distances $=2.23$ and $1.96 \AA$, respectively), while for positively charged Arg21 we observe an electrostatic contact. In the other snapshot of site I (Fig. 6), the CeK anion forms a doublehydrogen bonding interaction with two of the guanidinium $\mathrm{N}-\mathrm{H}$ groups of Arg21 involving a bridging oxygen of POM framework. The $\mathrm{NH}_{3}{ }^{+}$amino group of Lys96 forms a hydrogen bond with the POM, whereas the analogous Lys97 is bound via an electrostatic-type interaction showing $\mathrm{N}-\mathrm{H}-\mathrm{O}_{\text {Pom }}$ angles $<108^{\circ}$. Similarly, for site // (Fig. 7), the CeK complexation occurs via multiple binding interactions such as hydrogen bonding with Thr43, Thr51 and Tyr53 (O-H $\cdots \mathrm{O}_{\mathrm{POM}}$ distances ranging from 1.85 to $2.42 \AA$ ), and electrostatic with Arg45 and Arg68. Within these snapshots, the polar uncharged amino acids serine tyrosine, and threonine show computed interaction energies ranging from -37 to $-47 \mathrm{~kJ} \cdot \mathrm{mol}^{-1}$, which lie within the typical energy range for normal hydrogen bonds. ${ }^{[38]}$ For the positively charged arginines and lysines, the obtained interaction energies are two-fold higher (ranging from -71 to $-104 \mathrm{~kJ} \cdot \mathrm{mol}^{-1}$ ) and lie in the range of typical strong hydrogen bonds, which include the positive charge assisted hydrogen bonding $\mathrm{X}^{+}-\mathrm{H} \cdots \mathrm{A} .{ }^{[38]}$
(A)

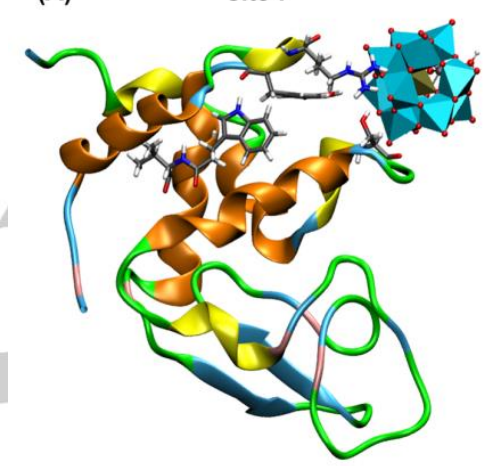

(B)

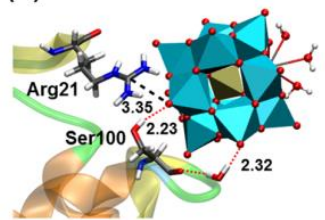

(C)

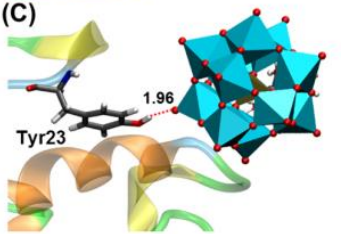

Figure 5. Illustrative snapshot of CeK...HEWL interaction at the vicinity of site $I$ involving Tyr23 (red area in Fig. 4) taken at 17066 ps of run 1 (interaction energy $\left.-237 \mathrm{~kJ} \cdot \mathrm{mol}^{-1}\right)$. Left panel highlights interacting amino acids and cleavage site I (Trp28 and Val29). Right panels: closer look at the interaction between CeK and amino acids Arg21, Ser100 and Tyr23 (-71, -47 and -38 $\left.\mathrm{kJ} \cdot \mathrm{mol}^{-1}\right)$. Distances in $\AA$.
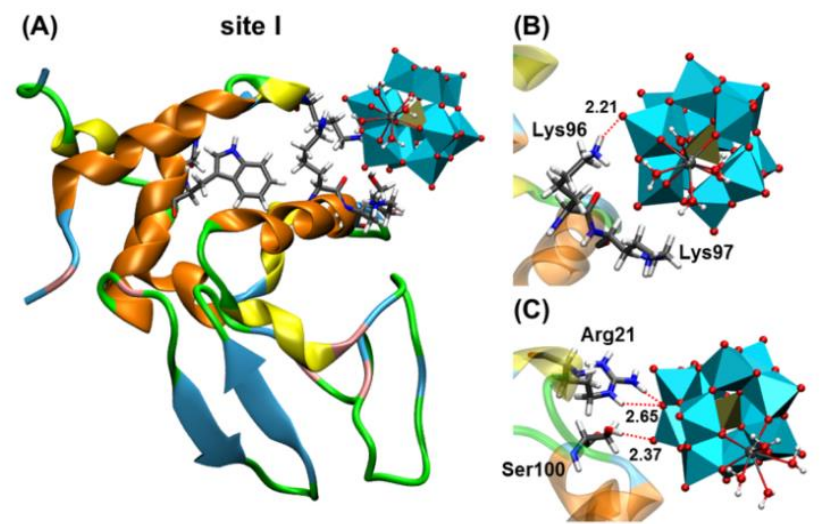

Figure 6. Illustrative snapshot of CeK...HEWL interaction at the vicinity of site I involving Lys96 and Lys97 (blue area in Fig. 4) taken at 19384 ps of run 5 (interaction energy $-304 \mathrm{~kJ} \cdot \mathrm{mol}^{-1}$ ). Left panel highlights interacting amino acids and cleavage site I (Trp28 and Val29). Right panels: closer look at the interaction between CeK and amino acids Arg21, Lys97, Lys96 and Ser100 ($104,-88,-76$ and $\left.-37 \mathrm{~kJ} \cdot \mathrm{mol}^{-1}\right)$. Distances in $\AA$.

We have analysed the formation of hydrogen bonds along the whole simulation in more detail. Fig. 3 shows the simulated 
hydrogen bond persistences as a precentatge of the trajectory (lines). For each residue we quantified the number of snapshots showing $\mathrm{H}$-bonding to $\mathrm{CeK}$ whose value was normalized by the total number of snapshots and used as representation of the overall CeK...HEWL $\mathrm{H}$-bond statistics. The $\mathrm{H}$-bond criteria comprise a distance $(<3.5 \AA)$ and an angle $\left(\mathrm{X}-\mathrm{H}-\mathrm{O}_{\text {POM }}>130^{\circ}\right)$ constraint. This parameter provides information on the most strongly interacting amino acids and the nature of their interaction, complementing the average energies reported in Fig. 3. The longest-lasting and the strongest interactions are with Arg21 for site I and Arg45 and Arg68 for site II. This agrees with previous NMR results showing resonance shifts for arginine side chains in the presence of POM. ${ }^{[39]}$ The interaction with these amino acids combines electrostatic and hydrogen-bonding contributions. For example although the interaction with Arg21 is present during the whole simulation (see Fig. S3), the persistence represents only $57 \%$. The affinity of the CeK anion increases by additional hydrogen bonding with the side chains of Ser100 and Tyr23 in site I and Thyr53 and Thr43 in site II, with percentage persistence ranging from 20 to $40 \%$. We could also identify other non-polar amino acids, such as glycine and alanine that interact appreciably with the CeK, via the $\mathrm{N}-\mathrm{H}$ amide group, the most outstanding being Gly102 and Gly104 with percentage persistence between 10 and $20 \%$ (see Fig. 3). It should be noted that although it had been proposed that hydrogen-bonding might be an interaction force in POMs binding to biomolecules, ${ }^{[19],[40]}$ this is the first time that these interactions have been quantified.
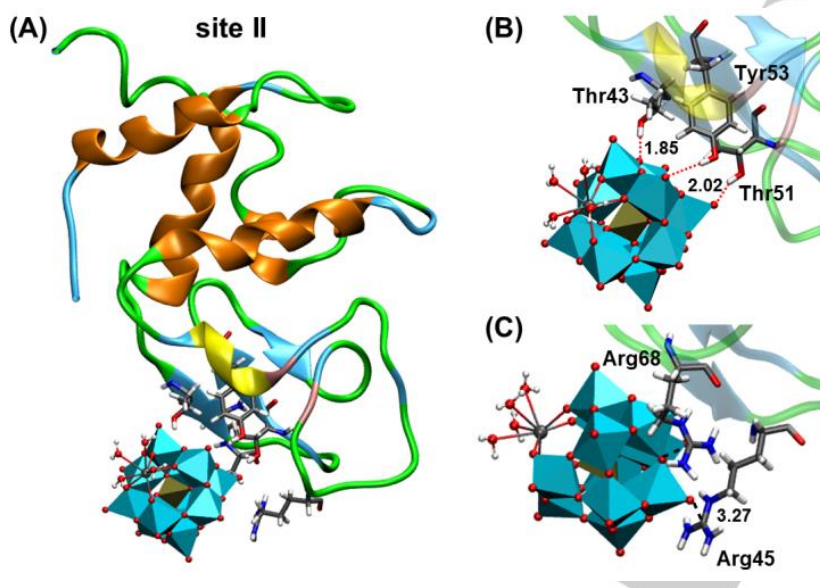

Figure 7. Illustrative snapshot of CeK $\cdots \mathrm{HEWL}$ interaction at the vicinity of site // taken at $18870 \mathrm{ps}$ of run 1 (interaction energy $-313 \mathrm{~kJ} \cdot \mathrm{mol}^{-1}$ ). Left panel highlights interacting amino acids and cleavage site II (Asn44 and Arg45). Right panels: closer look at the interaction between CeK and amino acids Arg45, Arg68, Tyr53, Thr43 and Thr51 (-77, -93, -46, -39 and $\left.-39 \mathrm{~kJ} \cdot \mathrm{mol}^{-1}\right)$. Distances in $\AA$.

In the crystal structure, the Zr-substituted $\left[\mathrm{PW}_{11} \mathrm{O}_{39} \mathrm{Zr}\left(\mathrm{OH}_{2}\right)_{n}\right]^{3-}$ anions showed direct hydrogen-bond interactions with HEWL, and also, water-mediated interactions, in which a layer of water molecules connected the CeK anion and the protein. There are other X-ray structures in which the interactions between the POMs and the protein are partially mediated by the solvent. ${ }^{[41]}$ For example, the octamolybdate and the hexatungstotellurate anions interact partially via water molecules with uncharged polar amino acids such as glutamine and threonine in the molybdenum storage $\operatorname{protein}^{[41] \mathrm{a}}$ and abPPO4 mushroom tyrosinase, ${ }^{[41][40] \mathrm{b}}$ respectively. Since the interaction of the POM with the solvent decreases as the interaction with the protein increases, the optimal situation might be the water-mediated contact in which the CeK anion keeps the first solvation shell and there is still a non-bonding electrostatic interaction with the positively charged amino acids. Fig 8 presents a sequence of snapshots taken during the approach of CeK anion to site /l as illustrated by the evolution of interaction energies in Fig. 2. In the frames of Fig. 8, we can observe different water-mediated interactions with Arg45, Arg68 and Thr43; and how the successive removal of the water layer surrounding the POM reduces the CeK $\cdots$ water interaction energy, which is balanced by the increase of the direct contact with the protein residues. Overall, both experiments and simulations indicate that electrostatic-based water-mediated interactions are quite favourable. However, in the dynamic process the CeK anion can easily remove the solvation shell to reach the protein surface, stabilized via hydrogen bonding with polar and positively charged amino acids. Analogously, other Xray structures have shown that the POMs are also able to interact directly with the protein. Rompel et al. ${ }^{[42]}$ have cocrystallized HEWL with the Anderson-Evans-type hexatungstotellurate $\left[\mathrm{TeW}_{6} \mathrm{O}_{24}\right]^{6-}$ anion which binds to positively charged (Arg and Lys) or polar uncharged residues (Asn and Gln) similarly to $\mathrm{CeK}$ anion in our simulations. Interestingly, they identified a specific cationic site formed by Arg45 and Arg68 where the hexatungstate binds similarly to $\mathrm{CeK}$ at site II. Also the analogous anion $\left[\mathrm{W}_{12} \mathrm{O}_{40} \mathrm{H}_{2}\right]^{6-}$ binds NTPDase1 directly interacting with Lys, Asn and GIn. ${ }^{[43]}$
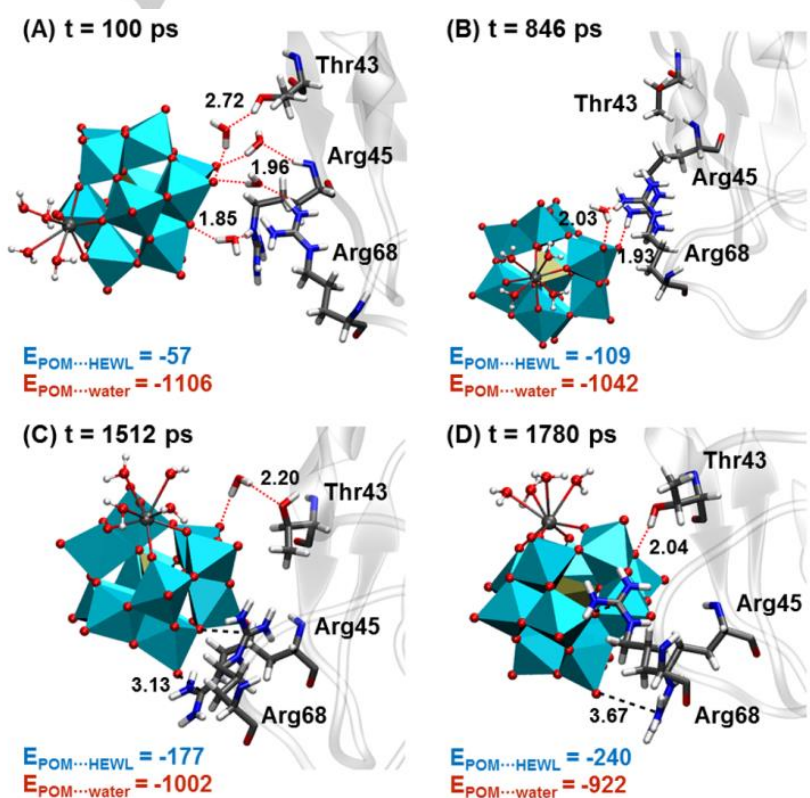

Figure 8. Snapshots taken during the approach of CeK anion to protein site II. For clarity, only selected water molecules are shown. Distances in $\AA$ and energies in $\mathrm{kJ} \cdot \mathrm{mol}^{-1}$.

The CeK anion interaction does not induce any conformational change in the HEWL structure and we only observed small geometrical differences in the side chains. This agrees with NMR studies indicating that HEWL structure was preserved upon binding to the analogous Keggin-type $\mathrm{Zr}$ - 
substituted anion. ${ }^{[20]}$ Thus, for the available simulation times, we cannot expect to observe a direct interaction of CeK with site / (Trp28-Val29) site which would involve a modification of protein secondary structure. However, the observed binding site at Arg21 might be related to an entrance channel to the solventinaccessible site I via secondary structure decrease of the $\alpha$ helix. For site II, the long and strong interaction with Arg45 is quite noteworthy because it belongs to the cleavage site II. As in the X-ray structure, the catalytically active $\mathrm{Ce}(\mathrm{IV})$ centre points towards the solvent due to the hydrophilicity of the $\mathrm{Ce}$ (IV)-aqua moiety. Consequently, the dynamic hydrolysis process should involve anion reorganization to bind the amide oxygen with the corresponding energy penalty. Nevertheless, the direct interaction of CeK to cleavage site // revealed in this study is consistent with the hydrolytic selectivity observed at Asn44Arg45 bond.

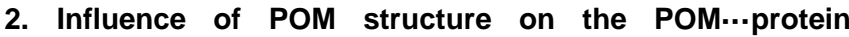 interactions.}

To get further insight into how POM features such as the shape, the size, the charge, the kind of incorporated metal ion and ligands can affect the interaction between POMs and proteins, we compared the behaviour of the $\mathrm{CeK}$ anion with the $\mathrm{Ce}(\mathrm{IV})$ substituted Keggin dimer $\left[\mathrm{Ce}\left(\mathrm{PW}_{11} \mathrm{O}_{39}\right)_{2}\right]^{10-}\left(\mathrm{CeK}_{2}\right)$, and the $\mathrm{Zr}(\mathrm{IV})$-substituted Lindqvist anion, $\left[\mathrm{W}_{5} \mathrm{O}_{18} \mathrm{Zr}\left(\mathrm{OH}_{2}\right)(\mathrm{OH})\right]^{3-}(\mathrm{ZrL})$. The dimeric $\mathrm{CeK}_{2}$ anion is in fact the species used for peptide hydrolysis, and it differs from CeK anion in that it carries greater negative charge and is larger and more extended. It also plaussible that the enzyme-like recognition of the POM occurs before the dimeric $\mathrm{CeK}_{\mathbf{2}}$ species dissociates into $\mathrm{CeK}$, and then interaction with protein promotes the hydrolysis of $\mathbf{C e K}_{2}$. The ZrL species represents a POM structure with smaller size and a different transition-metal substitution, which was also active towards the peptide bond hydrolysis in proteins. ${ }^{[12],[13],[44]}$ Moreover, in POM chemistry the charge/metal ratio parameter $(\mathrm{q} / \mathrm{M})$ has been used to set structure activity relationships ${ }^{[16],[46]}$ because it reflects better charge density distribution on the oxide structure. For the three selected POMs, the values are: 0.25 , 0.43 and 0.50 for $\mathrm{CeK} \mathrm{CeK}_{2}$ and $\mathrm{ZrL}$, respectively.

Table 1. Comparison of the HEWL affinity of the three POMs: CeK, CeK $\mathbf{C}_{2}$ and ZrL. Estimated from the percentage of POM.. HEWL contact persistence, interaction strength during the contact and the non-bonding interaction with the solvent per solvent-accessible atom. Energies in $\mathrm{kJ} \cdot \mathrm{mol}^{-1}$. [a]

\begin{tabular}{|c|c|c|c|c|c|c|}
\hline \multirow[b]{2}{*}{ anions } & \multirow[b]{2}{*}{$q / M$} & \multirow[b]{2}{*}{ Esolv } & \multicolumn{2}{|c|}{ \%time binding } & \multicolumn{2}{|c|}{ Int. strength } \\
\hline & & & site I & site II & site I & site II \\
\hline$\left[\mathrm{PW}_{11} \mathrm{Ce}\right]^{3-}(\mathbf{C e K})$ & 0.25 & -27 & $99 \%$ & $99 \%$ & -178 & -161 \\
\hline$\left[\mathrm{Ce}\left(\mathrm{PW}_{11}\right)_{2}\right]^{10-}\left(\mathrm{CeK}_{2}\right)$ & 0.43 & -43 & $90 \%$ & $95 \%$ & -260 & -224 \\
\hline$\left[\mathrm{W}_{5} \mathrm{Zr}\right]^{3-}(\mathrm{ZrL})$ & 0.50 & -54 & $56 \%$ & $69 \%$ & -168 & -187 \\
\hline
\end{tabular}

[a] The values are quantified every 4 ps time frame over 100 ns MD trajectories.

Our simulations showed that POMs bind proteins mainly by electrostatic interactions; however we anticipated that the interaction with the solvent, as well as the size of the system allowing several interactions to occur simultaneously, also need to considered. In fact, Nadjo et al. have recognized that the overall charge of the cluster is not the single parameter governing the binding process when comparing the binding of Human Serum Albumin (HSA) with POMs of different atomistic composition: $\quad\left[\mathrm{P}_{2} \mathrm{~W}_{17} \mathrm{O}_{61}\right]^{10-}, \quad\left[\mathrm{CuP}_{2} \mathrm{~W}_{17} \mathrm{O}_{61}\right]^{8-}, \quad\left[\mathrm{NiP}_{2} \mathrm{~W}_{17} \mathrm{O}_{61}\right]^{8-}$, $\left[\mathrm{H}_{2} \mathrm{~W}_{12} \mathrm{O}_{40}\right]^{6-}$ and $\left[\mathrm{NaP}_{5} \mathrm{~W}_{30} \mathrm{O}_{110}\right]^{14-[46]}$ Table 1 compares the simulated percentage of POM $\cdots$ HEWL interaction persistence for the three POMs which reflects their binding affinity to the protein. We quantified the number of snapshots in which the POM is closer than $3.5 \AA$ to the protein and normalized by the total number of snapshots. Roughly, the higher the charge density ( $q / M$ ratio), the lower the binding affinity of the POM, indicating that the less hydrophilic character of the anion might favour its protein affinity in water solution. In fact, the $\mathrm{q} / \mathrm{M}$ ratio correlates with the computed POM solvation energies per solvent-accessible atom (Table 1), measured as the average non-bonding interactions with the solvent when the POM is not in contact with the protein. The solvent-accessible atoms consist of the terminal and bridging oxygen atoms of the POM, and the ligands on the imbedded metal. Table 1 also compares the interaction strengths, measured as the average of POM $\cdots \mathrm{HEWL}$ interaction energies when the POM is in contact with the protein (POM $\cdots$ HEWL distance < $3.5 \AA$ ). The CeK anion shows higher affinity for $\mathrm{HEWL}$ than $\mathrm{CeK}_{2}$ and $\mathrm{ZrL}$ anions. The highly hydrophilic and small ZrL anion exhibits shorter persistence values (56 and 69\% for site I and II) compared to CeK because the solvation energy becomes higher while the interaction strength with HEWL remains similar (Table 1). The protein affinity of $\mathbf{C e K}_{2}$ anion lies in an intermediate situation with persistence values (90 and 95\% for site I and II) closer to CeK anion. The computed solvation energy of $\mathbf{C e K}_{2}$ is significantly higher due to its hydrophilicity, which however, is partially balanced by the stronger interaction strength due to the increase of interactions with multiple residues (see below for more details).

Fig. 9 compares the average interaction energies of the POMs with the individual amino acids. For $\mathbf{C e K}_{2}$ and $\mathbf{Z r L}$ anions, the most strongly interacting residues are also Arg21, Lys96 and Lys97 for simulations at site I and Arg45 and Arg68 for simulations at site II. In general, the $\mathrm{CeK}_{2}$ anion shows the higher average interaction energies (green bars) than those for CeK anion (yellow bars) and much higher than those for ZrL (blue bars). Their interactions with the proteins involve mainly hydrogen bond-mediated direct contacts with the side chains of positively charged amino acids such as arginine and lysine, and polar ones such as serine and tyrosine (see Fig. 10 and 11 for representative interactions of $\mathbf{C e K}_{2}$ and $\mathbf{Z r L}$ ). Therefore, these electrostatic interactions in the form of hydrogen bonding might be generalized in the binding of POMs to proteins, as recent review on the use of POMs in protein crystallography indicates. ${ }^{[47]}$ Nevertheless among the POM series, we found remarkable differences on the extent, the strength and the type of interaction with protein that can be directly related to the POM composition.

In the simulation of $\mathrm{CeK}_{2}$ anion at site I, the POM interacts mainly with Arg21 as it was observed for CeK, but because of its greater size additional strong interaction appears with other amino acids such as Lys96 and Lys97 where the two Keggin units operate simultaneously (see Fig. 10 for representative snapshot). This makes the interaction strength significantly higher than that for CeK (-260 vs. $-178 \mathrm{~kJ} \cdot \mathrm{mol}^{-1}$ in Table 1). Interestingly, the additive effect of the two Keggin units can induce some structural changes in the protein. At the POM binding site, the protein structure opens leading to a more 


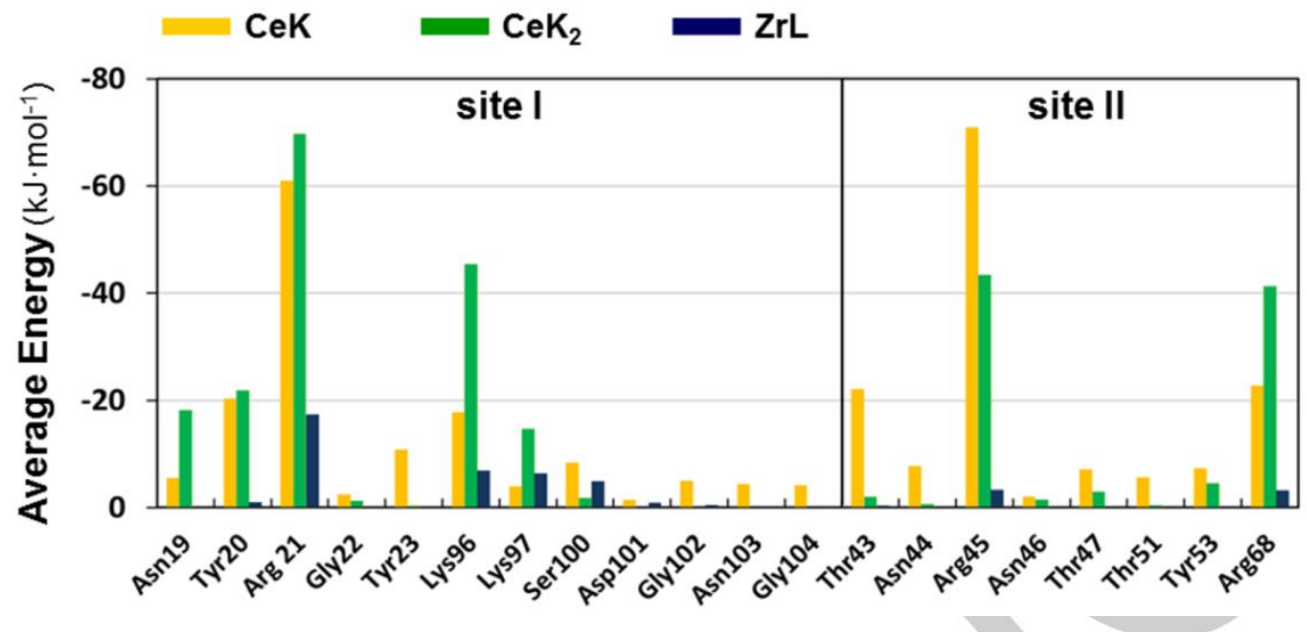

Figure 9. Comparison of amino acid specific POM $\cdots$ HEWL interactions for CeK (yellow bars), CeK ${ }_{2}$ (green bars) and ZrL (blue bars) anions. Average nonbonding interaction energies in $\mathrm{kJ} \cdot \mathrm{mol}^{-1}$ computed for snapshots taken every $4 \mathrm{ps}$ from the $100 \mathrm{~ns}$ of sampling.

accessible entrance channel to the cleavage site I (see Fig. 10, left). Fig. 12 shows that the root mean square deviation (RMSD) of the backbone portion involving the residues directly interacting with the POMs at site I (Tyr20, Arg21, Gly22, Tyr23, Lys96 and Lys97) is significantly larger for $\mathrm{CeK}_{2}$ than for CeK and ZrL. This kind of conformational process might initiate a secondary structure decrease of the a-helical part required to expose the cleavage site I to the hydrolysis catalyst. In the case of the simulation of the $\mathrm{CeK}_{2}$ anion at site II, the anion does not stay interacting with Arg45 as reflected in the low average interaction energy (Fig. 9). Instead, the anion is released into the solution and/or it moves through protein surface interacting with other cationic sites. Compared to interaction occurring at the vicinity of site I, here the topology of the protein does not allow $\mathrm{CeK}_{2}$ anion interaction with the two Keggin units simultaneously. Consequently, the POM has a larger surface exposed to the solvent that pulls the whole POM towards the bulk of the solution. Thus, the interaction strength at site $/ /\left(-224 \mathrm{~kJ} \cdot \mathrm{mol}^{-1}\right)$ is weaker than that of $\mathrm{CeK}_{2}$ for site I $\left(-260 \mathrm{~kJ} \cdot \mathrm{mol}^{-1}\right)$.
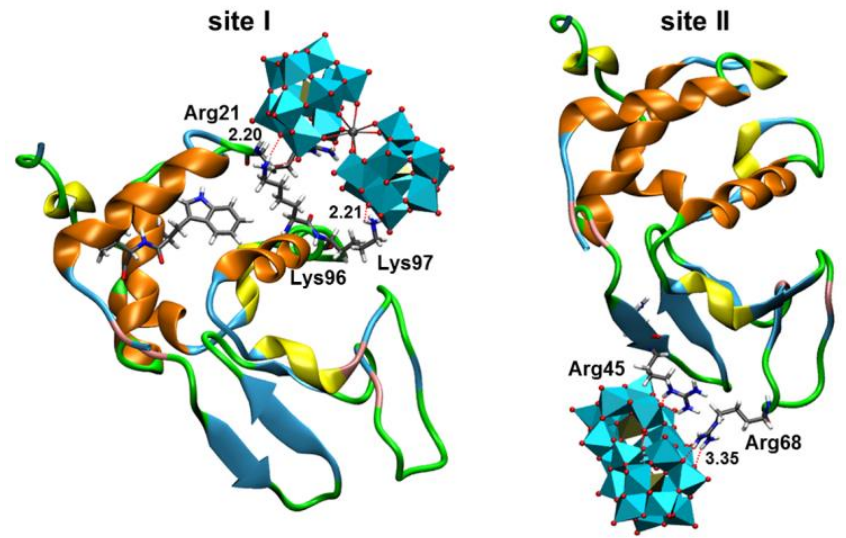

Figure 10. Illustrative snapshots of $\mathrm{CeK}_{2} \cdots \mathrm{HEWL}$ interaction at site I and II taken at 10494 ps of run 1 and 11924 ps of run1, respectively (interaction energies -408 and $\left.-283 \mathrm{~kJ} \cdot \mathrm{mol}^{-1}\right)$. Left panel highlights the most strongly interacting amino acids for simulation at site I: Arg21, Lys96 and Lys97 (-108, 88 , and $\left.-120 \mathrm{~kJ} \cdot \mathrm{mol}^{-1}\right)$. Right panel highlights those for simulation at site II: Arg45 and $\operatorname{Arg} 68\left(-123\right.$ and $\left.-117 \mathrm{~kJ} \cdot \mathrm{mol}^{-1}\right)$. Distances in $\AA$.
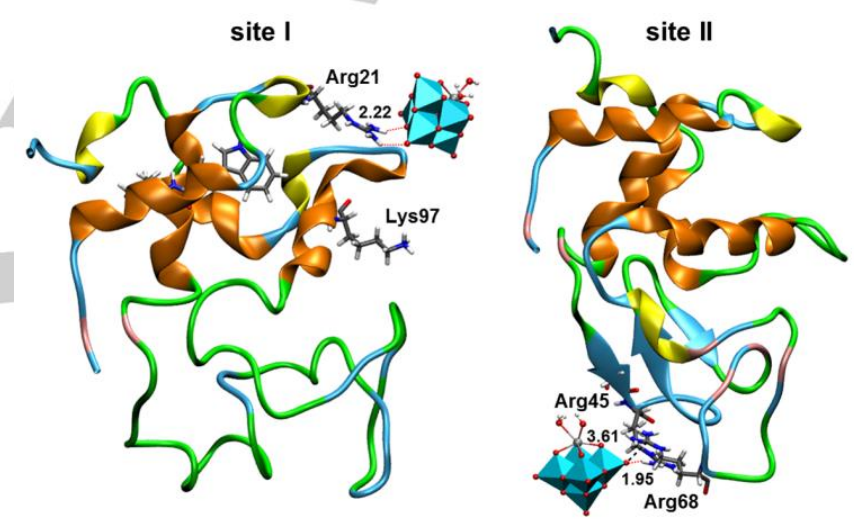

Figure 11. Illustrative snapshots of ZrL $\cdots H E W L$ interaction at the vicinity of site $I$ and II taken at 40 ps of run 1 and 560 ps of run 1 , respectively (interaction energies -120 and $-195 \mathrm{~kJ} \cdot \mathrm{mol}^{-1}$ ). Left panel highlights the most strongly interacting amino acid for simulation at site I: Arg21 $\left(-85 \mathrm{~kJ} \cdot \mathrm{mol}^{-1}\right)$. Right panel highlights those for simulation at site II: Arg45 and Arg68 (-69 and $\left.-114 \mathrm{~kJ} \cdot \mathrm{mol}^{-1}\right)$. Distances in $\AA$.

The interaction mode of $\mathbf{Z r L}$ anion with the protein resembles that of $\mathbf{C e K}$; the basic oxygen atoms of the POM framework form hydrogen bonds and the $\mathrm{Zr}$-substituted moiety mostly points towards the solvent (see Fig. 11). However, the persistence of the interactions is significantly shorter as reflected by the average interaction energies with individual residues in Fig. 9. The smaller size of the anion does not allow ZrL to interact simultaneously with several residues so effectively. For example in site I, the anion interacts alternatively with Arg21 and Lys97 jumping from one residue to the other. However, the interaction strength of $\mathbf{Z r L}\left(-168 \mathrm{~kJ} \cdot \mathrm{mol}^{-1}\right)$ is similar to that of CeK $\left(-178 \mathrm{~kJ} \cdot \mathrm{mol}^{-1}\right)$ because the higher charge density of $\mathbf{Z r L}$ atoms can lead to stronger interactions with individual amino acids. 
Figure 12. RMSDs of the protein backbone involved in the interaction site I

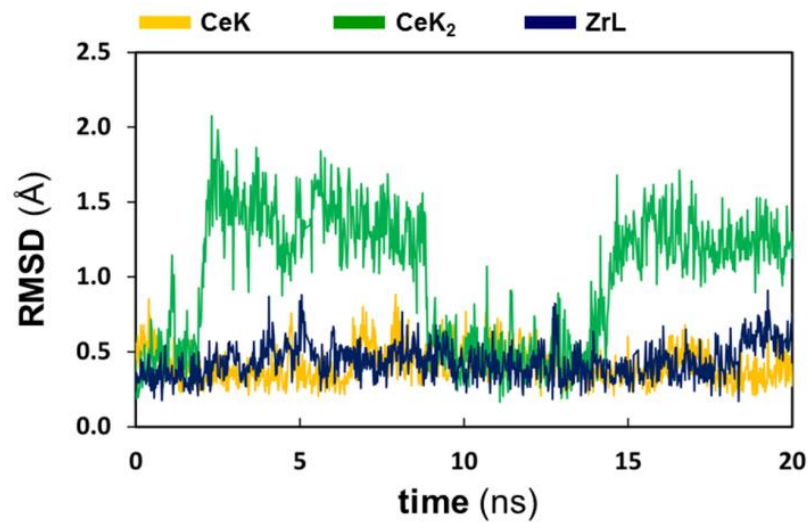

(residues: $20,21,22,23,96,97$ ) as a function of simulation time for a selected run of 20 ns. Simulations for CeK (yellow line), $\mathbf{C e K}_{2}$ (green line) and ZrL (blue line) anions.

\section{Conclusions}

In this work we report for the first time the use of molecular dynamics (MD) simulations to analyse the interaction between proteins and polyoxometalates by using the specific case of hen egg-white lysozyme (HEWL) and three different POMs including $1: 1$ and 1:2 Ce(IV)-monosubstituted Keggin POMs (CeK and $\mathrm{CeK}_{2}$, respectively) and $\mathrm{Zr}(\mathrm{IV})$-monosubstituted Lindqvist POM (ZrL).

In the MD simulations with the CeK anion, we have identified two sites of the protein in which the POM interacts strongly that can be related to the observed selectivity in hydrolytic activity of $\mathrm{Ce}(\mathrm{IV})$ - and $\mathrm{Zr}(\mathrm{IV})$-substituted POMs towards the Trp28-Val29 (site I) and Asn44-Arg45 (site II) bonds. The CeK anion interacts strongly with Arg21 at an entrance channel to the cleavage site I buried in a hydrophobic pocket, and with Arg45 directly at site II. Both interactions occur through the POM framework with the catalytically active $\mathrm{Ce}$ (IV) centre pointing towards the solvent due to the hydrophilicity of its aqua ligands. This is in full agreement with the X-ray structures obtained from the recent co-crystallization of HEWL and a Zr-substituted Keggin-type POM. ${ }^{[20]}$ Thus, the modeling also established a relationship between the non-bonding electrostatic type interaction of the CeK anion with HEWL and the observed selectivity of the hydrolysis.

In general, the interaction of POMs with HEWL involves charge attraction and hydrogen boding of the basic oxygen atoms of POM framework with the side chains of positively charged amino acids (arginine and lysine) and of polar uncharged amino acids (tyrosine, serine and asparagine). The formation of hydrogen bonding with the $\mathrm{N}-\mathrm{H}$ amide group of the main protein chain is also plausible, although its extent is less important. Moreover, depending on the size and shape of the polyoxoanion the cooperative effects, in which several amino acids interact simultaneously with the oxide framework, are enhanced or decreased.

The protein affinity of the CeK anion is higher than for $\mathbf{C e K}_{2}$ and $\mathrm{ZrL}$ anions. The Keggin-type CeK anion is less hydrophilic reducing the solvation energies and it has the right size and shape for accepting the additive effect of several amino acids simultaneously. The larger and more charged dimeric $\mathbf{C e K}_{2}$ anion has more charge density and larger solvent-accessible surface that increases its hydrophilicity and reduces its affinity to proteins. However, the $\mathrm{CeK}_{2}$ anion can interact very strongly with some sections of the protein through its two dimeric units at once, causing some structural changes in HEWL. They can include an opening of the entrance channel to cleavage site I that could expose the peptide bond to be hydrolysed. The smaller ZrL anion has high charge density that increases its hydrophilicity, and in addition, its size and shape do not allow interaction with several amino acids simultaneously so effectively causing the lowest protein affinity among the series of studied POMs. Thus, these simulations demonstrated that an optimal interaction POM...protein should balance charge and size. In addition, the study proves the feasibility of this computational approach, opening up new opportunities to study another range of other POM $\cdots$ protein interaction and other chemical processes.

\section{Acknowledgements}

We acknowledge support from the Spanish Ministry of Science and Innovation (grant CTQ2014-52774-P) and the Generalitat de Catalunya (2014SGR199 and XRQTC). T.N.P.V. acknowledges KU Leuven and FWO Flanders for financial support. J.J.C., V.G. and T.N.P. also acknowledge the COST Action CM1203 (PoCheMoN). J. M. P. thanks ICREA foundation for an ICREA ACADEMIA Award.

Keywords: polyoxometalate $\cdot$ protein $\bullet$ molecular dynamics $•$ DFT • peptide hydrolysis

[1] M. T. Pope, Heteropoly and isopoly oxometalates, Springer-Verlag, New York, 1983

[2] a) D. L. Long, R. Tsunashima, L. Cronin, Angew. Chem., Int. Ed., 2010, 49, 1736-1758; b) A. Proust, R. Thouvenot, P. Gouzerh, Chem. Commun. 2008, 1837-1852; c) N. Mizuno, K. Yamaguchi, Chem. Rec. 2006, 6, 12-22.

[3] For some reviews, see: a) S. S. Wang, G. Y. Yang, Chem. Rev., 2015 115 , 4893-4962H; b) Lv, Y. V. Geletii, C. Zhao, J. W. Vickers, G. Zhu, Z. Luo, J. Song, T. Lian, D. G. Musaev, C. L. Hill, Chem. Soc. Rev. 2012, 41, 7572-7589.

[4] For some reviews, see: a) A. Proust, B. Matt, R. Villanneau, G Gillemont, P. Gouzerh, G. Izzet, Chem. Rev., 2012, 41, 7605-7622; b) Y. F. Song, R. Tsunashima, Chem. Rev., 2012, 41, 7384-7402; c) Y Wang, I. A. Weinstock, Chem. Rev., 2012, 41, 7479-7496.

[5] For some reviews, see: a) H. Stephan, M. Kubeil, F. Emmerling, C. E. Muller, Eur. J. Inorg. Chem., 2013, 1585-1594; b) M. Aureliano, G. Franqueza, C. A. Ohlin, Dalton Trans., 2013, 42, 11770-11777; c) J. T. Rhule, C. L. Hill, D. A. Judd, Chem. Rev., 1998, 98, 327-358.

[6] a) I. Y. Skobelev, O. V. Zalomaeva, O. A. Kholdeeva, J. M. Poblet, J. J. Carbó, Chem. Eur. J., 2015, 21, 14496-14506; b) P. Jimenez-Lozano, I. D. Ivanchikova, O. A. Kholdeeva, J. M. Poblet and J. J. Carbó, Chem. Commun., 2012, 48, 9266-9268; c) O. A. Kholdeeva, Eur. J. Inorg. Chem., 2013, 1595-1605; d) N. Antonova, J. J. Carbó, U. Kortz, O. A Kholdeeva, J. M. Poblet, J. Am. Chem. Soc, 2010, 132, 7488-7497; e) B. G. Donoeva, T. A. Trubitsina, N. S. Antonova, J. J. Carbó, J. M. Poblet, G. Al-Kadamany, U. Kortz, O. A. Kholdeeva, Eur. J. Inorg Chem. 2010, 5312-5317; f) O. A. Kholdeeva, G. M. Maksimov, R. I. Maksimovskaya, M. P. Vanina, T. A. Trubitsina, D. Y. Naumov, B. A Kolesov, N. S. Antonova, J. J. Carbó, J. M. Poblet, Inorg. Chem., 2006, 45, 7224-7234.

[7] a) H. Lv, J. Song, Y. V. Geletii, J. W. Vickers, J. M. Sumliner, D. G. Musaev, P. Koegerler, P. F. Zhuk, J. Bacsa, G. Zhu, C. L. Hill, J. Am Chem. Soc., 2014, 136, 9268-9271; b) J. Soriano-López, S. GobernaFerron, L. Vigara, J. J. Carbó, J. M. Poblet, J. R. Galán-Mascarós, 
Inorg. Chem., 2013, 52, 4753-4755; c) S. Goberna-Ferron, L. Vigara, J. Soriano-López, J. R. Galán-Mascarós, Inorg. Chem., 2012, 51, 11707 11715 ; d) Q. Yin, J. M. Tan, C. Besson, Y. V. Geletii, D. G. Musaev, A E. Kuznetsov, Z. Luo, K. I. Hardcastle, C. L. Hill, Science, 2010, 328, 342-345; e) Y. V. Geletii, B. Botar, P. Koegerler, D. A. Hillesheim, D. G. Musaev, C. L. Hill, Angew. Chem. Int. Ed., 2008, 47, 3896-3899; f) A Sartorel, M. Carraro, G. Scorrano, R. De Zorzi, S. Geremia, N. D. McDaniel, S. Bernhard, M. Bonchio, J. Am. Chem. Soc., 2008, 130 5006-5007.

[8] a) Q. Chen, L. Yang, C. Zheng, W. Zheng, J. Zhang, Y. Zhou and J. Liu, Nanoscale, 2014, 6, 6886-6897; b) J. Iqbal, M. Barsukova-Stuckart, M. Ibrahim, S. U. Ali, A. A. Khan and U. Kortz, Med. Chem. Res., 2013, 22 , 1224-122

[9] a) J. Thygesen, S. Weinstein, F. Francesci, A. Yonath, Structure 1996 4, 513-518; b) Bashan, A. Yonath, J. Mol. Struct. 2008, 890, 289-294 c) D. Janell, A. Tocilj, I. Kölln, F. Schlünzen, M. Glühmann, H. A. S. Hansen, J. Harms, A, Bahan, I. Agmon, H. Bartels, M. Kessler, S Weinstein, F. Franceschi, A. Yonath, in Polyoxometalate Chemistry, M. T. Pope and A. Müller, Eds., 2001, 391-415, Kluwer Academic Publishers.

[10] a) T. L. H. Giang, G. Absillis, S. R. Bajpe, J. A. Martens, T. N. ParacVogt, Eur. J. Inorg. Chem., 2013, 4601-461; b) T. L. Hong Giang, G. Absillis and T. N. Parac-Vogt, Dalton Trans., 2013, 42, 10929-10938; c) G. Absillis and T. N. Parac-Vogt, Inorg. Chem., 2012, 51, 9902-9910; d) S. Vanhaecht, G. Absillis, T. N. Parac-Vogt, Dalton Trans., 2012 10028-10034.

[11] K. Stroobants, E. Moelants, H. G. T. Ly, P. Proost, K. Bartik and T. N. Parac-Vogt, Chem. Eur. J., 2013, 19, 2848-2858.

[12] a) K. Stroobants, G. Absillis, E. Moelants, P. Proost and T. N. Parac Vogt, Chem. Eur. J., 2014, 20, 3894-3897; b) K. Stroobants, V. Goovaerts, G. Absillis, G. Bruylants, E. Moelants, P. Proost and T. N Parac-Vogt, Chem. Eur. J., 2014, 20, 9567-9577.

[13] H. G. T. Ly, G. Absillis, R. Janssens, P. Proost, T. N. Parac-Vogt, Angew. Chem. Int. Ed., 2015, 54, 7391-7394.

[14] a) V. Goovaerts, K. Stroobants, G. Absillis and T. N. Parac-Vogt, J. Inorg. Biochem., 2015, 150, 72-80; b) K. Stroobants, D. Saadallah, G. Bruylants, T. N. Parac-Vogt, Phys. Chem. Chem. Phys., 2014, 16 21778-21787

[15] a) K. Stroobants, V. Goovaerts, G. Absillis, G. Bruylants, E. Moelants, P. Proost and T. N. Parac-Vogt, Chem. Eur. J., 2014, 20, 9567-9577; b) K. Stroobants, G. Absillis, E. Moelants, P. Proost and T. N. Parac-Vogt, Chem. Eur. J., 2014, 20, 3894-3897.

[16] a) X. López, J. J. Carbó, C. Bo and J. M. Poblet, Chem. Soc. Rev. 2012, 41, 7537-7571; b) X. López, P. Miró, J. J. Carbó, A. RodríguezFortea, C. Bo and J. M. Poblet, Theor. Chem. Acc., 2011, 128, 393-404

[17] a) K. Narasimhan, S. Pillay, N. R. B. Ahmad, Z. Bikadi, E. Hazai, L. Yan P. R. Kolatkar, K. Pervushin, R. Jauch, ACS Chem. Biol., 2011, 6, 573 581 ; b) R. Prudent, C. F. Sautel, C. Cochet, Biochim. Biophys. Acta, 2010, 1804, 493-498; c) R. Prudent, V. Moucadel, B. Laudet, C. Barette L. Lafanechere, B. Hasenknopf, J. Li, S. Bareyt, E. Lacote, S. Thorimbert, M. Malacria, P. Gouzerh, C. Cochet, Chem. Biol., 2008, 15, 683-692; d) D. Hu, C. Shao, W. Guan, Z. Su, J. Sun, J. Inorg. Biochem., 2007, 101, 89-94; e) T. Tiago, P. Martel, C. Gutierrez-Merino, M. Aureliano, Biochim. Biophys. Acta, 2007, 1774, 474-480; f) R. J. Pezza, M. A. Villarreal, G. G. Montich, C. E. Argaña, Nucleic Acids Research, 2002, 30,4700-4708; g) D. A. Judd, J. H. Nettles, N. Nevins, J. P. Snyder, D. C. Liotta, J. Tang, J. Ermolieff, R. F. Schinazi, C. L. Hill, J. Am. Chem. Soc., 2001, 123, 886-897; h) S. G. Sarafianos, U. Kortz, M. T. Pope, M. J. Modak, Biochem. J., 1996, 319, 619-626.

[18] a) M. Li, C. Xu, J. Ren, E. Wang, X. Qu, Small, 2013, 9, 3455-3461; b) H. F. Pu, E. Wang, H. Jiang, J. Ren, Mol. BioSyst., 2013, 9, 113-120; c) Inomata, E. Itoh, K. Unoura, RSC Adv., 2013, 3, 21271-21274; d) J. Geng, M. Li, J. Ren, E. Wang, X. Qu, Angew. Chem. Int. Ed., 2011, 50, 4184-4188; e) Q. Wu, J. Wang, L. Zhang, A. Hong, J. Ren, Angew. Chem., Int. Ed., 2005, 44, 4048-4052.

[19] a) T. Zhang, H.-W. Li, Y. Wu, Y. W., L. Wu, Chem. Eur. J., 2015, 21, 9028-9033; b) H.-W. Li, Y. Wang, T. Zhang, Y. Wu, L. Wu, Chem PlusChem. 2014, 79, 1208-1213.
[20] A. Sap, E. De Zitter, L. Van Meervelt and T. N. Parac-Vogt, Chem. Eur. J., 2015, 21, 11692-11695.

[21] a) B. Hess, C. Kutzner, D. van der Spoel, E. Lindahl, J. Chem. Theory Comput., 2008, 4, 435-447; b) D. Van Der Spoel, E. Lindahl, B. Hess G. Groenhof, A. E. Mark and H. J. C. Berendsen, J. Comput. Chem. 2005, 26, 1701-1718; c) H. J. C. Berendsen, D. van der Spoel, R. van Drunen, Comput. Phys. Commun., 1995, 91, 43-56.

[22] J. M. Wang, P. Cieplak, P. A. Kollman, J. Comput. Chem., 2000, 21, 1049-1074.

[23] a) A. Chaumont, G. Wipff, Phys. Chem. Chem. Phys., 2008, 10, 6940 6953; b) A. Chaumont, G. Wipff, J. Phys. Chem. C, 2009, 113, 18233 18243; c) A. Chaumont, G. Wipff, C. R. Chimie, 2012, 15, 107-117.

[24] a) F. Leroy, P. Miró, J. M. Poblet, C. Bo, J. Bonet Ávalos, J. Phys Chem. B, 2008, 112, 8591-8599; b) X. López, C. Nieto-Draghi, C. Bo, J. B. Avalos, J. M. Poblet, J. Phys. Chem. A, 2005, 109, 1216-1222.

[25] M. J. Frisch et al., Gaussian 09, revision C.01; Gaussian, Inc. Wallingford CT, 2010. G. W. T. M. J. Frisch, H. B. Schlegel, G. E. Scuseria, M. A. Robb, J. R. Cheeseman, G. Scalmani, V. Barone, B. Mennucci, G. A. Petersson, H. Nakatsuji, M. Caricato, X. Li, H. P. Hratchian, A. F. Izmaylov, J. Bloino, G. Zheng, J. L. Sonnenberg, M Hada, M. Ehara, K. Toyota, R. Fukuda, J. Hasegawa, M. Ishida, T. Nakajima, Y. Honda, O. Kitao, H. Nakai, T. Vreven, J. A. Montgomery, J. E. Peralta, F. Ogliaro, M. Bearpark, J. J. Heyd, E. Brothers, K. N Kudin, V. N. Staroverov, R. Kobayashi, J. Normand, K. Raghavachari A. Rendell, J. C. Burant, S. S. lyengar, J. Tomasi, M. Cossi, N. Rega, J. M. Millam, M. Klene, J. E. Knox, J. B. Cross, V. Bakken, C. Adamo, J. Jaramillo, R. Gomperts, R. E. Stratmann, O. Yazyev, A. J. Austin, R. Cammi, C. Pomelli, J. W. Ochterski, R. L. Martin, K. Morokuma, V. G. Zakrzewski, G. A. Voth, P. Salvador, J. J. Dannenberg, S. Dapprich, A D. Daniels, Farkas, J. B. Foresman, J. V. Ortiz, J. Cioslowski, D. J. Fox.

[26] a) A. D. Becke, Phys. Rev. A, 1988, 38, 3098-3100; b) J. P. Perdew, Phys. Rev. B, 1986, 33, 8822-8824.

[27] P. J. Hay, W. R. Wadt, J. Chem. Phys., 1985, 82, 270-283.

[28] a) X. Cao and M. Dolg, J. Mol. Struct., 2002, 581, 139-147; b) M. Dolg, H. Stoll, H. Preuss, J. Chem. Phys., 1989, 90, 1730-1734.

[29] E. Cancès, B. Mennucci and J. Tomasi, J. Chem. Phys., 1997, 107 3032-3041.

[30] A. K. Rappe, C. J. Casewit, K. S. Colwell, W. A. Goddard, W. M. Skiff, J. Am. Chem. Soc., 1992, 114, 10024-10035.

[31] P. Jiménez-Lozano, J. J. Carbó, A. Chaumont, J. M. Poblet, A. Rodríguez-Fortea, G. Wipff, Inorg. Chem., 2014, 53, 778-786.

[32] E. Pechkova, S. K. Tripathi and C. Nicolini, Comparison of Lysozyme Crystals Grown by APA and Classical Hanging Drop Method, DOI: 10.2210/pdb2213ijv/pdb.

[33] W. L. Jorgensen, J. Chandrasekhar, J. D. Madura, R. W. Impey, M. L. Klein, J. Chem. Phys., 1983, 79, 926-935.

[34] T. Darden, D. York and L. Pedersen, J. Chem. Phys., 1993, 98, $10089-$ 10092.

[35] H. J. C. Berendsen, J. P. M. Postma, W. F. van Gunsteren, A. DiNola, J. R. Haak, J. Chem. Phys., 1984, 81, 3684-3690.

[36] R. W. Hockney, S. P. Goel, J. Eastwood, J. Quiet J. Comp. Phys. 1974, 14, 148-158.

[37] B. Hess, H. Bekker, H. J. C. Berendsen, J. G. E. M. Fraaije, J. Comp. Chem. 1997, 18, 1463-1472.

[38] T. Steiner, Angew. Chem. Int. Ed., 2002, 41, 48-76.

[39] R. M. Smith, D. E. Hansen, J. Am. Chem. Soc. 1998, 120, 8910-8913.

[40] Y. Zhou, L. Zheng, F. Han, G. Zhang, Y. Ma, J. Yao, B. Keita, P. de Oliveira and L. Nadjo, Colloids Surf., A, 2011, 375, 97-101.

[41] a) B. Kowalewski, J. Poppe, U. Demmer, E. Warkentin, T. Dierkes, U Ermler, K. Schneider, J. Am. Chem. Soc., 2012, 134, 9768-9774; b) S G. Mauracher, C. Molitor, R. Al-Oweini, U. Kortz and A. Rompel, Crystallogr. Sect. D, 2014, 70, 2301-2315.

[42] A. Bijelic, C. Molitor, S. G. Mauracher, R. Al-Oweini, U. Kortz, A Rompel, ChemBioChem, 2015, 16, 233-241.

[43] M. Zebisch, M. Krauss, P. Schafer and N. Strater, Acta Cryst., 2014 D70, 1147-1154.

[44] A. Sap, G. Absillis and T. N. Parac-Vogt, Dalton Trans., 2015, 44 1539-1548. 
[45] X. López, J. A. Fernández, J. M. Poblet, Dalton Trans., 2006, 1162 1167.

[46] a) G. Zhang, B. Keita, C. T. Craescu, S. Miron, P. de Oliveira and L. Nadjo, Biomacromolecules, 2008, 9, 812-817; b) G. Zhang, B. Keita, C T. Craescu, S. Miron, P. de Oliveira and L. Nadjo, J. Phys. Chem. B, 2007, 111, 11253-11259.

[47] A. Bijelic and A. Rompel, Coord. Chem. Rev., 2015, 299, 22-38. 


\section{Entry for the Table of Contents}

Layout 1:

\section{FULL PAPER}

The molecular interactions between polyoxometalates (POMs) and proteins have been described at atomic level by molecular dynamics simulations for the first time. We evaluated how POM features such as the shape, the size, the charge or the type of incorporated metal influence these interactions. The POM with the higher protein affinity is less hydrophilic and it has the right shape for establishing interactions with several residues simultaneously

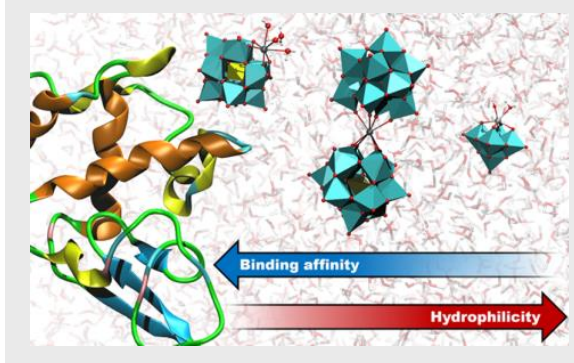

Albert Solé-Daura, Vincent Goovaerts, Karen Stroobants, Gregory Absillis, Pablo Jiménez-Lozano, Josep $M$. Poblet, Jonathan D. Hirst, Tatjana N. Parac-Vogt, Jorge J. Carbó*

Page No. - Page No.

Probing polyoxometalate-protein interactions using molecular dynamics simulations 